\title{
Optimal Investment of Resources in Creation of Human Capital: A Control Theoretic Approach
}

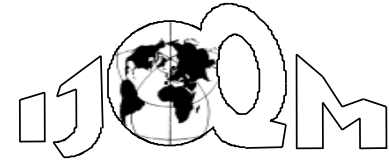

Volume 25, Number 4

December 2019, pp. 239-252
Udayan Chanda

Praveen Goyal

BITS Pilani, India

(udayanchanda@pilani.bits-pilani.ac.in)

(praveen.goyal@pilani.bits-pilani.ac.in)

Many recent studies on organizational development have suggested that human capital attributes have a strong and direct effect on organizational performance. Thus, a cost-effective optimal human capital development plan can be of utmost importance for a firm to sustain in this competitive environment. Herein, we studied the optimal investment path on human capital under a given budgetary constraint to improve the organizational performance. Cobb-Douglas production functions (of human capital) are used to derive the optimal time path of a firm's investment by employing optimal control theory. The economic explanations and suggestions of the model solutions are also discussed in detail. We expect the experimental results obtained through the analysis will assist us to recognize the importance of each chosen parameter and their credence.

Keywords: Human Capital Development, Optimal Investment, Cobb-Douglas Production function, Optimal Control Theory, Hamiltonian

\section{Introduction}

"The 2018 Global Human Capital Trends report sounds a wake-up call for organizations. The rise of the social enterprise requires a determined focus on building social capital by engaging with diverse stakeholders, accounting for external trends, creating a sense of mission and purpose throughout the organization, and devising strategies that manage new societal expectations. At stake is nothing less than an organization's reputation, relationships and ultimately, success or failure” (2018 Deloitte Global Human Capital Trends, pp.9) ${ }^{1}$. Human capital can be defined as the acquirement of the required skills, knowledge, and ability through appropriate training and education to enhance individual productivity and create economic value. Youndt, Snell, Dean and Lepak (1996) suggested that in manufacturing firms' employee skills and commitment are the key contributors to the value creation process. Thus a firm needs to focus more on human capital to improve the efficiency and potential of its employees to get better performance. Ulrich (1998) suggested that investment in human capital enhances the competency of an employee and gives the firm a competitive edge in the continually increasing

1 https://www2.deloitte.com/content/dam/insights/us/articles/HCTrends2018/2018HCtrends_Rise-of-the-social-enterprise.pdf 
competitive business environment. Firms invest in human capital to develop professional skills and to create abilities of the employees and that enhances satisfaction and helps to increase productivity.

Black and Lynch (1996) using data from the National Center on the Educational Quality of the Workforce (EQW), National Employers' Survey suggested that investments in the quality of the workforce play an important role to increase output in both, the manufacturing and non manufacturing sectors. Redding (1996) suggested that a lack of investment in education and training are closely related to firms' investments in product quality. Lepak and Snell (1999) argued that not all employees acquire similar skills or are equally important to a particular firm and hence it is important for a firm to provide distinct and necessary skill sets to employees to improve performance. Bosma, Praag, Thurik and Wit (2004) suggested that human and social entrepreneurship-specific capital investments can enhance industry specific performance. Wan (2007) suggested that it is important for a firm to provide skill building training to employees on regular basis to improve job performance and human capital development to continue viable in the period of globalization. Yang, Lin and Ma (2010) recommended that the quality of human capital vis-à-vis productivity can be improved through on job training. Hence, special efforts should be given to investing more in human capital. Onkelinx, Manolova, Edelman (2016) argued to pursue rapid internationalization strategy, a firm needs to provide learning and training facilities to enhance employee productivity.

Becker and Gerhart (1996) argued that high performance work practices have an economically positive effect on firm performance. Becker and Huselid (1998) pointed out that due to a change in demand dynamics and organizational structure, the strategic importance of human capital has increased a manifold. Lee (2000) suggested that career development factors and employees' level of job satisfaction are strongly associated. Wright and Boswell (2002) argued that a firm's HR practices should support Human Capital Development to achieve the desired strategic success. Wan (2007) observed that a firm's investment in human capital development is positively affecting employee satisfaction. Author argued that the satisfaction of an employee is connected to a firm's profitability, productivity, employee retention, and customer satisfaction. Chanda and Goyal (2019) in their analysis found that Organization Human capital practices are linked to Employee Satisfaction, Employee Performance and Organizational Performance (OP). Odhon'g, and Omolo (2015) empirically established the positive relationship between human capital investment and organizational performance. In their study, authors also observed that all the human capital attributes viz education, training, knowledge management and skills developments have a strong relationship with the organizational performance. In this research article, we tried to suggest an optimal path to invest in human capital under given budgetary constraints, so that the overall organizational performance can be improved.

Dobell and Ho (1967) discussed the economic problem of funds allocation between capital accumulations and labour training using optimal control theory. The results of their analysis showed that apart from the preliminary phase of capital insufficiency, it is optimal to invest in human capital to attain full employment at the earliest. Razin (1972) suggested that an increase in productivity happens due to the investment in human capital and learning by doing phenomenon. The author 
discussed the issue of the optimal accumulation of human capital under different scenarios using optimal control theory. Ritzen and Winkler (1979) discussed the problem of optimal allocation of limited school resources to maximize the human capital stock of students at the end of the schooling period. Using optimal controltheoretic approach authors suggested different measures to allocate resources amongst education sectors by government. Hartl (1983) discussed the optimal allocation of resources problem to maximize the production of human capital for students under limited budgetary constraints using optimal control theory. The author used various types of functions to express human capital and suggested several optimal measures for effective resource allocation to increase the stock of human capital. Though the above works are highly successful to optimize the human capital investment using the growth curve phenomenon but the above research has been mostly restricted within the education sector. In contrast, we proposed that a similar approach can be used at the individual level to address the question of how a manufacturing firm should allocate resources to identify the optimal path of human capital development to optimize the organizational performance.

One of the objectives of this study is to investigate and suggest an optimal method of resource allocation in the production of human capital under the given budgetary constraint so that the productivity of labour force can be increased. The optimal time path of a firm's investment using Cobb-Douglas production functions (of human capital) is derived by employing optimal control theory. The economic interpretations and implications of the model solution are also discussed in detail. The paper is organized as follows. In section 2 formulation of the model is discussed in detail, which is further analyzed in Section 3. In section 4 we conclude the article with a discussion on the extension and limitations and future avenues of this research.

\section{Model Formulation}

In this section, we formulate the budget allocation problem. The proposed model is based on a very minimal number of assumptions. We assumed that the total value of a firm's production of goods can be expressed as a function of labour input and capital input. Labour input can be defined as a function of the average stock of human capital and the number of employed workers whereas capital input can be defined as a function of the value of the physical capital stock.

Let $O(t)$ is the value of production at time ' $t$ '.

$C(t)$ is the average stock of human capital at time ' $t$ '.

$K(t)$ is the value of physical capital at time ' $t$ '.

$E(t)$ is the number of employed workers at time ' $t$ '.

$x(t)$ is the average training cost per employee at time ' $t$ '.

$A$ is the measure of the productivity of the economy

$\alpha$ is the output elasticity.

$B$ is the fixed allocated budget for training and skill development

Dropping the time notation and using the Cobb-Douglas Augmented production function, the value of production can be expressed as:

$$
O=A f(K, C E)=A K^{\alpha}(C E)^{1-\alpha}=\left(A C^{1-\alpha}\right) K^{\alpha} E^{1-\alpha}
$$


If $G(t)$ is the rate of investment in physical capital and $I(t)$ is the investment in human capital, then $G(t)$ and $I(t)$ can be defined as (Dobell and Ho, 1967)

$$
G=\dot{K}+\delta K
$$

Where $\delta$ is the investment rate required to maintain the capital stock at the existing level.

Here, it is assumed that to maintain a constant level of employment $E$, it is necessary to train $\mu E$ number of employees per year. Hence total investment on newly trained employees can be given as

$$
I=x(\dot{E}+\mu E)
$$

Where, $\mu$ is a constant.

Thus, the instantaneous stream of return ' $R(t)^{\prime}$ at any time ' $t$ ' can be given as

$R=O-G-I=A f(K, C E)-(\dot{K}+\delta K)-x(\dot{E}+\mu E)=\left(A C^{1-\alpha}\right) K^{\alpha} E^{1-\alpha}-$ $(\dot{K}+\delta K)-x(\dot{E}+\mu E)$

$\therefore$ The instantaneous stream of return per employee at any time ' $t$ ' can be given as $=\frac{R}{E}$

If we assume $C(t)=C_{0}$, then the change in human capital over time can be given by (Hartl [9])

$\frac{d C}{d t}=\dot{C}=-\beta C+f(C, x)$

$\beta$ is the constant rate of knowledge depreciation and $f$ represents the human capital production function and can be defined using Cobb-Douglas function of knowledge, as follows (dropping time notation)

$f(C, x)=\gamma C^{a} x^{1-a}$

Where, $\gamma$ and $a$ are constant $(0<a<1)$.

Since $B$ is already fixed, hence it can be defined as

$B=\int_{0}^{T} e^{-r s} x(s) d s$

If $Q(t)$ denotes the remaining fund from the allocated budget at any given time ' $t$ ', then $Q(t)$ can be expressed as

$Q(t)=B-\int_{0}^{T} e^{-r s} x(s) d s$, where $Q(0)=B$ and $Q(T)=0$ 
$\Rightarrow \frac{d Q(t)}{d t}=\dot{Q}(t)=-e^{-r t} x(t)$

The objective here is to suggest an optimal policy for resource allocation in the production of human capital over the fixed time interval under limited budget such that the discounted total stream of return and terminal stock of human capital

$J=\int_{0}^{T} e^{-r t}\left(\frac{R(t)}{E(t)}\right) d t+e^{-r T} C(T)$

is maximized, subject to

$\dot{C}(t)=-\beta C(t)+f(C(t), x(t))$

$\dot{Q}(t)=-e^{-r t} x(t)$

where, $r$ is the discount rate. Functions (12) and (13) are twice differentiable, and

$f_{x}\left(=\frac{\partial f}{\partial x}\right)>0, f_{x x}\left(=\frac{\partial^{2} f}{\partial^{2} x}\right)<0, f_{C C}\left(=\frac{\partial^{2} f}{\partial^{2} C}\right)<0$

\section{Solution by the Maximum Principle}

In this section, we have used Pontryagin Maximum principle to explain the above problem. Dropping the time notation, the current value Hamiltonian can be written as

$H=\frac{R}{E}+\lambda_{1} \dot{C}+\lambda_{2} \dot{Q}=\frac{R}{E}+\lambda_{1}(-\beta C+f(C, x))+\lambda_{2}\left(-e^{-r t} x\right)$

where, $\lambda_{1}$ and $\lambda_{2}$ are the current-value costate variable (adjoint functions of $C$ and $Q$ respectively) that satisfies the differential equations

$\dot{\lambda}_{1}=r \lambda_{1}-H_{c}$

$\dot{\lambda}_{2}=r \lambda_{2}-H_{Q}(17)$

with the transversality condition at

$t=T, \lambda_{1}(T)=1$

We have, $H_{c}=\frac{\partial H}{\partial C}=\frac{1}{E} R_{C}+\lambda_{1}\left(-\beta+f_{C}(C, x)\right)=\frac{1}{E}\left(A(1-\alpha) C^{-\alpha} K^{\alpha} E^{1-\alpha}\right)+$ $\lambda_{1}\left(-\beta+\gamma a C^{a-1} x^{1-a}\right)=A(1-\alpha)\left(\frac{K}{C E}\right)^{\alpha}+\lambda_{1}\left(-\beta+\gamma a C^{a-1} x^{1-a}\right)$

And,

$H_{Q}=\frac{\partial H}{\partial Q}=0$ 
From, (16) - (20), we have

$$
\begin{aligned}
& \dot{\lambda}_{1}=\lambda_{1}\left(r+\beta-\gamma a C^{a-1} x^{1-a}\right)-A(1-\alpha)\left(\frac{K}{C E}\right)^{\alpha} \\
& \dot{\lambda}_{2}=r \lambda_{2}
\end{aligned}
$$

The physical explanation of the current value Hamiltonian can be given as follows $\lambda_{1}$ and stands for the future benefits of investment in training for a new addition in the human capital stock and $\lambda_{2}$ also stands for the future benefits from investment in the human capital production process (at time ' $t$ '). Thus, the current value Hamiltonian signifies the instant total profit at a time ' $t$ ' on the net investment for the human capital production process.

Solving the equation (21) and (22) with the terminal condition $\lambda_{1}(T)=1$ and $\lambda_{2}(T)=0$ we have

$\lambda_{1}=\left(\int A\left(\frac{K}{C E}\right)^{\alpha} e^{-\left(\int\left(r+\beta-\gamma C^{a-1} x^{1-a}\right) d t\right)}(\alpha-1) d t+v_{1}\right) e^{\int\left(r+\beta-\gamma C^{a-1} x^{1-a}\right) d t}$

$\lambda_{2}=v_{2} e^{r t}$

Where $v_{1}$ and $v_{2}$ are constants. For an optimal non-negative $x$ we have the first order necessary condition that

$$
\begin{aligned}
& H_{x}=\frac{\partial H}{\partial x}=0 \\
& \Rightarrow \frac{R_{x}}{E}+\lambda_{1} f_{x}(C, x)-\lambda_{2} e^{-r t}=0 \\
& \Rightarrow \frac{1}{E}(-(\dot{E}+\mu E))+\lambda_{1} \gamma C^{a}(1-a) x^{-a}-\lambda_{2} e^{-r t}=0 \\
& \Rightarrow x^{*}=e^{\frac{a \ln (C)-\ln \left(\frac{-\lambda_{2} E e^{-r t}-(\dot{E}+\mu E)}{\lambda_{1} \gamma E(a-1)}\right)}{a}}
\end{aligned}
$$

The second order condition for $H$-maximization is $H_{x x}<0$

Equation (27) can be interpreted as an optimal investment in human capital at any point of time $x^{*}$ is a function of the current level of human capital stock and the cost of training to maintain the desired level of human capital stock.

\section{The Optimal Trajectories of Firm's Budget on Human Capital over Time}

The information obtained in the previous section is used here to derive the firm's optimal trajectories of investment in training and skill development over time. By taking the time derivative of the optimal the average training cost per employee in 
equation (26), we obtain the relative change in average training cost per employee over time:

$$
\begin{aligned}
& \frac{d}{d t}\left(\frac{1}{E}(-(\dot{E}+\mu E))+\lambda_{1} \gamma C^{a}(1-a) x^{-a}-\lambda_{2} e^{-r t}\right)=0 \\
& \Rightarrow-\frac{E(\ddot{E}+\mu \dot{E})-(\dot{E}+\mu E) \dot{E}}{E^{2}}+\dot{\lambda}_{1} f_{x}+\lambda_{1} f_{x x} \dot{x}-\dot{\lambda}_{2} e^{-r t}+r \lambda_{2} e^{-r t}=0 \\
& \Rightarrow \dot{x}=\frac{\frac{1}{E^{2}}\left(E \ddot{E}-\ddot{E}^{2}\right)-\dot{\lambda}_{1} f_{x}+\dot{\lambda}_{2} e^{-r t}-r \lambda_{2} e^{-r t}}{\lambda_{1} f_{x x}}
\end{aligned}
$$

From equation (7), we have

$$
f_{x}=\gamma C^{a}(1-a) x^{-a}>0 \text { and } f_{x x}=-a \gamma C^{a}(1-a) x^{-(a+1)}<0
$$

From (30), depending on the sign of the numerator we have the following cases: Case 1

If $\frac{1}{E^{2}}\left(E \ddot{E}-\ddot{E}^{2}\right)-\dot{\lambda}_{1} f_{x}+\dot{\lambda}_{2} e^{-r t}-r \lambda_{2} e^{-r t} \leq 0$ then $\dot{x} \geq 0$

i.e. $x(t)$ will be monotonically increasing. Equation (32) is possible

$$
\begin{aligned}
& \text { iff } \frac{1}{E^{2}}\left(E \ddot{E}-\ddot{E}^{2}\right) \leq \dot{\lambda}_{1} f_{x}-\dot{\lambda}_{2} e^{-r t}+r \lambda_{2} e^{-r t} \\
& \Rightarrow\left(\frac{\ddot{E}}{E}\right)\left(1-\frac{\ddot{E}}{E}\right) \leq \dot{\lambda}_{1} f_{x} \\
& \Rightarrow\left(\frac{\ddot{E}}{E}\right)\left(1-\frac{\ddot{E}}{E}\right) \leq\left(\lambda_{1}\left(r+\beta-\frac{a}{C} \gamma C^{a} x^{1-a}\right)-\right. \\
& \left.A C^{1-\alpha} K^{\alpha} E^{1-\alpha}\left(\frac{1-\alpha}{C E}\right)\right)\left(\frac{1-a}{x}\right) \gamma C^{a} x^{1-a} \\
& \Rightarrow\left(\frac{\ddot{E}}{E}\right)\left(1-\frac{\ddot{E}}{E}\right)\left(\frac{x}{1-a}\right) f+\left(\frac{1-\alpha}{C E}\right) O \leq \lambda_{1}\left(r+\beta-\frac{a}{C} f\right) \\
& \Rightarrow r+\beta \geq\left(\left(\frac{\ddot{E}}{E}\right)\left(1-\frac{\ddot{E}}{E}\right)\left(\frac{x}{1-a}\right) f+\left(\frac{1-\alpha}{C E}\right) O\right)+\frac{a}{C} f
\end{aligned}
$$

Equation (34) will hold under the condition that $r$ and $\beta$ is positive and $0<a<1$. The above result can be interpreted as under constant returns to scale, if the firm's objective is to maximize instantaneous stream of return per employee and human capital production then the firm should keep on investing more on employee skill development process when the summation of discount rate and depreciation rate is more than the organizational output and human capital production per employee. 


\section{Case 2}

If $\frac{1}{E^{2}}\left(E \ddot{E}-\ddot{E}^{2}\right)-\dot{\lambda}_{1} f_{x}+\dot{\lambda}_{2} e^{-r t}-r \lambda_{2} e^{-r t} \geq 0$ then $\dot{x} \leq 0$

Under this condition $x(t)$ will be monotonically decreasing. Equation (35) will be true

$$
\begin{aligned}
& \frac{1}{E^{2}}\left(E \ddot{E}-\ddot{E}^{2}\right) \geq \dot{\lambda}_{1} f_{x}+\dot{\lambda}_{2} e^{-r t}-r \lambda_{2} e^{-r t} \\
& \Rightarrow r+\beta \leq\left(\left(\frac{\ddot{E}}{E}\right)\left(1-\frac{\ddot{E}}{E}\right)\left(\frac{x}{1-a}\right) f+\left(\frac{1-\alpha}{C E}\right) O\right)+\frac{a}{C} f
\end{aligned}
$$

Equation (38) will hold under the condition that the rate of knowledge depreciation is much lesser than organizational output and human capital production per employee. Under this circumstance, it can be suggested that the firm may lower the investment on the average training cost per employee to maximize the instantaneous stream of return per employee and human capital production.

\section{Case 3}

If $\frac{1}{E^{2}}\left(E \ddot{E}-\ddot{E}^{2}\right)-\dot{\lambda}_{1} f_{x}+\dot{\lambda}_{2} e^{-r t}-r \lambda_{2} e^{-r t}=0$ then $\dot{x}=0$

Under this condition $x(t)$ will attain saturation point. Equation (39) will be true

$$
r+\beta=\left(\left(\frac{\ddot{E}}{E}\right)\left(1-\frac{\ddot{E}}{E}\right)\left(\frac{x}{1-a}\right) f+\left(\frac{1-\alpha}{C E}\right) O\right)+\frac{a}{C} f
$$

\section{Empirical Observations}

In this section, we have tried to assess the impact of human capital and physical capital on the value of production (capacity utilization). To understand the relationship the conceptual model (equation1) is tested on cross-sectional data from the Indian manufacturing sector (data collected from Food, Textiles, Chemicals \& Chemical Products, Rubber \& Plastics Products, Non-Metallic Mineral Products, Fabricated Metal Products, Machinery \& Equipment, Basic Metals \& Metal Products, Electronics \& Communications Equip., Motor Vehicles and Other Manufacturing industry). In this section, we have also tried to tests empirically that imparting formal training influences the overall capacity utilization of an industry. To validate the proposed model, India specific data were used from Enterprise Surveys, The World Bank (http://www.enterprisesurveys.org) for the year 2014. The Enterprise Surveys, The World Bank studied the business environment of the Indian manufacturing sector using a representative sample of the non-agricultural formal private economy. They identified the inadequately educated workforce was one of the important business environment obstacles in India.

In our analysis, we first tried to assess whether the association between imparting formal training and capacity utilization is strong. We regress industry specific formal 
training data on capacity utilization data. Our empirical assessment on the value of production recognizes that there exists a positive correlation between proportions of workers offered formal training and productive capacity of a firm (0.74). Table 1 provides the sector wise empirical assessment of the impacts of formal training on the productive capacity of a firm (without considering other variables).

Table 1 Regression Fitting Result of Proportions of Workers Offered Formal Training on Capacity Utilization

\begin{tabular}{|l|c|c|c|c|}
\hline & Coefficients & $\begin{array}{c}\text { Standard } \\
\text { Error }\end{array}$ & $\boldsymbol{t}$ Stat & $\boldsymbol{P}$-value \\
\hline Intercept & 55.30600042 & 6.77215158 & 8.166681 & $3.04 \mathrm{E}-06$ \\
\hline $\begin{array}{l}\text { proportions of workers offered formal } \\
\text { training }\end{array}$ & 0.412424341 & 0.10952018 & 3.765738 & 0.002693 \\
\hline Correlation & \multicolumn{3}{|c|}{0.735967798} \\
\hline R Square & \multicolumn{3}{|c|}{0.541648599} \\
\hline
\end{tabular}

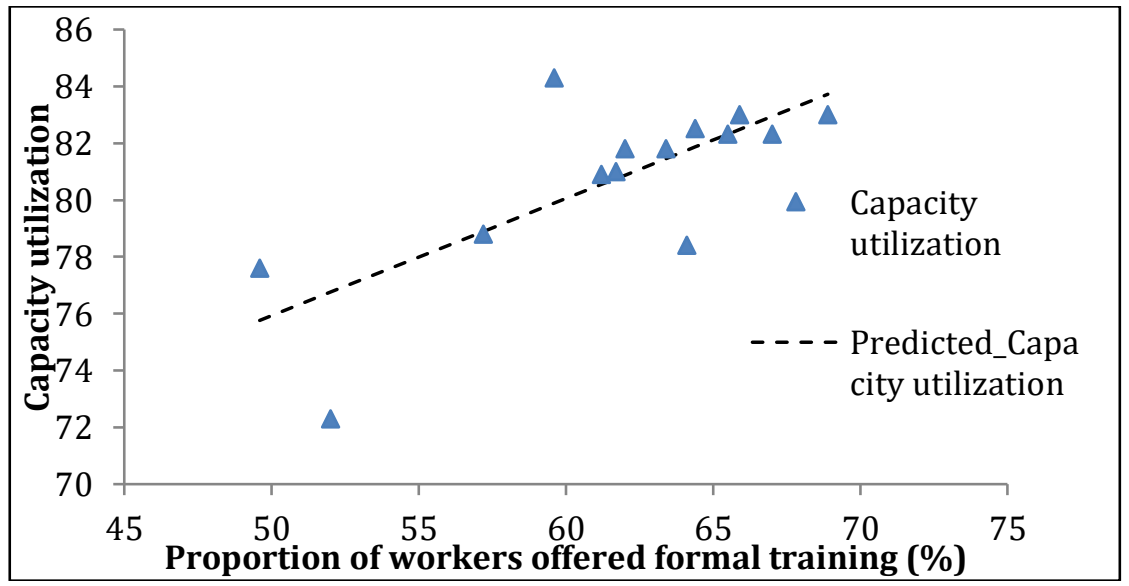

Figure1 Relationship between Proportions of Workers Offered Formal Training (\%) and Capacity Utilization

Figure1, shows the direct relationship between formal training and capacity utilization. From Table 1, we found that for one additional average increase in proportions of workers offered formal training sector wise capacity utilization improved by 0.41 units. Also, as expected, the impact of formal training on capacity utilization comes out to be highly significant.

Next, we tried to assess the influence of human capital and physical capital on the value of production (capacity utilization). To validate the model as described in equation1, we described human capital as a multiplication function of Percent of firms offering formal training and Number of workers. We also described the value of physical capital as Percent of firms owning fixed assets. Figure 2, present the 
Relationship among Capacity utilization, Value of Human Capital, and Value of Physical Capital. Table 2 presents the parameter estimates using the given model.

Table 2 Parameter Estimates

\begin{tabular}{|c|c|c|}
\hline Parameters & Estimate & Confidence Interval \\
\hline$A$ & 0.904229 & $(0.776846409,1.002597981)$ \\
\hline$\alpha$ & 0.082067 & $(0,0.170555059)$ \\
\hline
\end{tabular}

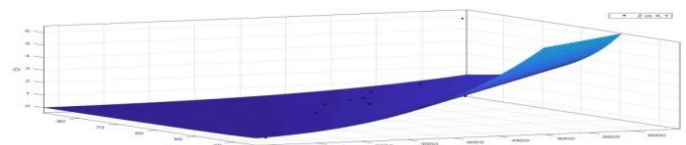

Figure 2 Relationship among Capacity Utilization, Value of Human Capital and Value of Physical Capital

Figure 2 shows a direct association between Capacity utilization, Value of Human Capital, and Value of Physical Capital. This suggests that increasing the value of human capital with physical capital will improve the value of production. The above analysis suggests that the combination of offering formal training and Number of workers and Percent of firms owning fixed assets can be considered a factor of the value of production. This gives us further impetus to discuss the policy implications of the model using numerical examples as discussed in the following section.

\section{Policy Implications using Numerical Examples}

Here we have discussed the optimal policies with the proposed model by considering several numerical illustrations. Initially, we have considered some base values of the model parameters. Afterward, sensitivity analysis has been performed on these parameters to identify the policy implications of the model. The initial approximations of model parameters are as follows

$$
C=90, a=0.5, E=100, \dot{E}=10, \lambda_{1}=10, \lambda_{2}=5, \mu=0.4, \gamma=0.1, r=0.5,
$$

In this section, the association between average training cost and the costate variable has been investigated analytically. Figure 3 represents 3D plot shows the relationship between the time and the costate variable (future benefits from investment on training for a new addition in the human capital stock) to the average training cost per employee. The above analysis suggests that the optimal investment in training during an initial period the lifecycle is very high and then the investment on the training reduces gradually over time (similar phenomenon observed by Blinder and Weiss 1976).

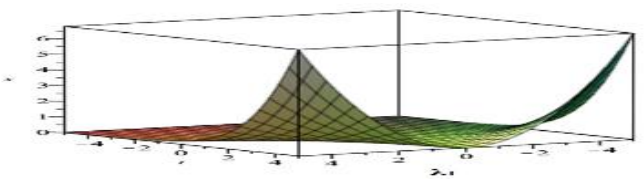

Figure 3 Optimal Trajectories of average Training Cost, Time and the Costate Variable 
Figure 3 represents that for shorter time interval and low future benefits from investment in training results in low average training cost. However, keeping a high costate variable with a long duration increases average training cost. The resulting trajectories of average cost due to costate variable and due to time (keeping other parameters constant) are presented separately in Figure 2 and Figure 3 respectively. In the analysis, it is also observed that under constant parameter values, as the value of $\lambda_{1}$ gradually increases with a fixed rate of increase in employees, the average training cost per employee increases considerably (as depicted in Figure 4) increasing the human capital production value.

We also investigated the path of the average training cost with respect to time. The result pointed out that with an increase in time, the average training cost per employee increases significantly till it attains the saturation point (as depicted in Figure 5) consequently the human capital production value also attains permeation point after a certain point of time. The above phenomenon is consistent with the work of Black, Noel and Wang (1999). Authors suggested that for large firms, initially, the average training cost is high and afterward when the firm hires more skilled workers, it starts using the expertise of coworkers to train the new employees. Similar patterns were observed all through the numerical analysis.

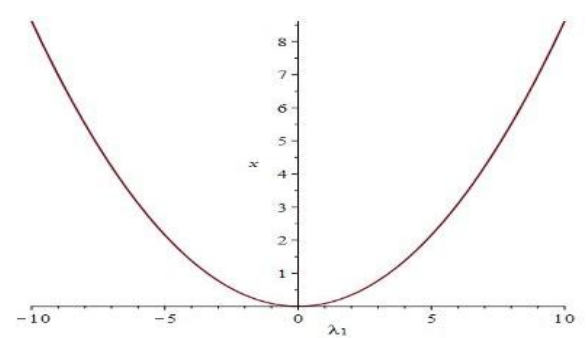

Figure 4 Optimal Trajectory of average Training Cost against the Costate Variable

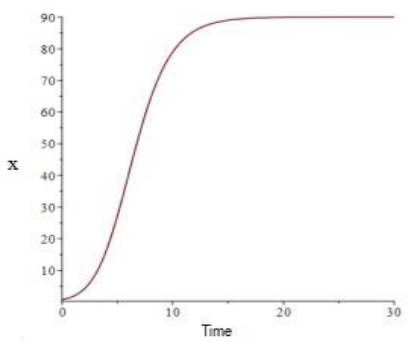

Figure 5 Optimal Trajectory of average Training Cost Against Time

\section{Conclusions}

In this paper, we discussed an optimal allocation plan to maximize the production of human capital under limited resources in a dynamic environment. Using control theoretic approach we tried to identify the optimal path of human capital development at an individual level to increase the productivity of labor force. The optimal time path of a firm's investment has been derived using the Cobb-Douglas 
production functions (of human capital). By the proposed methodology, the expenditure rate on human capital development can easily be controlled. We can also detect areas where more training is required in a specific time interval. Here, we also discussed the optimal distribution strategy of resources under a variety of scenarios by investigating the behavior of the model parameters. Detail optimization policy using the optimal control theory is discussed and validated using numerical examples. Based on the analysis, we observed that to optimize the instantaneous stream of return per employee, a firm must invest more in training and skill development, till the total value of discount rate and depreciation rate is more than the organizational output and human capital production per employee. During our analysis, we also observed that it is optimal for a firm to invest less in training and skill development if knowledge depreciation is lower than the organizational output and human capital production per employee.

The suggested areas for future work are as follows. One of the major limitations of the proposed work is the assumption of constant allocation of budget for training and skill development at any point in time. For a firm which is consistently increasing the workforce level until it achieves a desired human capital stock, keeping static budgetary condition for any point of time is a rather unrealistic assumption. The proposed framework has been validated based on some assumed parameter values, hence verifying the internal consistency of the model using other kinds of experiments can be further explored. The model can also be extended by using new control theoretic approaches that have been used for the allocation of resources under different environments.

\section{Acknowledgment}

The authors are thankful to the anonymous referees for their useful suggestions. This article was revised in light of the comments. This research is supported by the Indian Council of Social Science Research (02/136/ 2016-17/RPR).

\section{References}

1. Black, Sandra E., and Lisa M. Lynch, (1996) "Human Capital Investments and Productivity," American Economic Review, vol. 86, no. 2, pp. 263-267

2. Black, Dan, Noel, Brett J. and Wang, Zheng, (1999) "On-the-Job Training, Establishment Size, and Firm Size: Evidence for Economies of Scale in the Production of Human Capital", Southern Economic Journal, vol. 66, no. 1, pp. 82-100

3. Blinder, Alan and Weiss, Yoram. (1976) "Human Capital and Labor Supply: A Synthesis". Journal of Political Economy, vol. 84, no. 3, pp. 449-72.

4. Becker, B. and Gerhart, B., (1996). "The impact of human resource management on organisational performance: progress and prospects", Academy of Management Journal, vol. 39, pp. 779-801.

5. Becker, B. and Huselid, M.A. (1998), "High performance work systems and firm performance: a synthesis of research and managerial implications", Research in Personnel and Human Resource Management, vol. 16, pp. 53-101. 
6. Bosma, N. S., Van Praag, C. M., Thurik, A. R., and De Wit, G., (2004). "The value of human and social capital investments for the business performance of startups". Small Business Economics, vol. 23, pp. 227-236.

7. Chanda, U., \& Goyal, P. (2019). “Assessing Impact of Human Capital, SRHRM and Employee Related Factors on Firm Performance". Journal of Industrial Integration and Management, vol. 4, no 02, 1850018:1-35.

8. Dobell, A. and Ho, Y. (1967). "Optimal investment policy: An example of a control problem in economic theory”. IEEE Transactions on Automatic Control, vol. 12 , no. 1 , pp. 4-14.

9. Hartl, Richard F. (1983), "Optimal Allocation of Resources in the Production of Human Capital”, Journal of the Operational Research Society, vol. 34, no. 7 , pp. 599-606

10. Lee, S.H., (2000), "A managerial perspective of the objectives of HRM practices in Singapore: an exploratory study", Singapore Management Review, vol. 22, no. 1 , pp. 65-82.

11. Lepak, D. P., \& Snell, S. A. (1999). "The human resource architecture: Toward a theory of human capital allocation and development". Academy of Management Review, vol. 24, pp. 31-48.

12. Odhon'g, E.A \& Omolo, J. (2015). "Effect of Human Capital Investment on Organizational Performance of Pharmaceutical Companies in Kenya". Global Journal of Human Resources Management, vol. 3, no. 6, pp. 1-29.

13. Onkelinx, J., Manolova, T. S., \& Edelman, L. F. (2016). "The human factor: Investments in employee human capital, productivity, and SME internationalization”. Journal of International Management, vol. 22, pp. 351364.

14. Razin, Assaf. (1972) "Optimum Investment in Human Capital," The Review of Economic Studies, vol. 23, no. 4, pp. 455-60.

15. Redding, S. (1996). "The Low-Skill, Low-Quality Trap: Strategic Complementarities between Human Capital and R\&D," Economic Review, vol. 106, pp. 458-470.

16. Ritzen, J. M. and D. R. Winkler (1979). "On the optimal allocation of resources in the production of human capital", Journal of the Operational Research Society, vol. 30, no. 1, pp. 33-41.

17. Ulrich, D. (1988). "A new mandate for human resources". Harvard Business Review, vol. 76, no. 1, pp. 124-134.

18. Wan, H. L. (2007). "Human capital development policies: enhancing employees" satisfaction", Journal of European Industrial Training, vol. 31, no. 4, pp. 297-322.

19. Wright, P.M. and Boswell, W.R. (2002), "Desegregating HRM: a review and synthesis of micro and macro human resource management research", Journal of Management, vol. 28, pp. 247-76.

20. Yang, C. H., Lin, C. H., \& Ma, D. (2010). "R\&D, human capital investment and productivity: Firm-level evidence from China's electronics industry". China \& World Economy, vol. 18, pp. 72-89.

21. Youndt, M. A., Snell, S. A., Dean, J. W., Jr., \& Lepak, D. P. (1996). "Human resource management, manufacturing strategy, and firm performance". Academy of Management Journal, vol. 39, pp. 836-866. 


\section{About Our Authors}

Udayan Chanda is working as an Associate Professor in the Department of Management, Birla Institute of Technology and Science (BITS), Pilani. His research interests include marketing models, inventory modelling, software reliability growth modelling and dynamic optimisation techniques.

Praveen Goyal is working as an Assistant professor in Department of Management at BITS Pilani - Pilani Campus. His primary research and teaching areas are Stratgic Management, CSR, Corporate Sustainability, Marketing Performance and related areas. 